\title{
A Source of AGCM Bias in Simulating the Western Pacific Subtropical High: Different Sensitivities to the Two Types of ENSO
}

\author{
Houk PAEK AND Jin-Yi YU \\ Department of Earth System Science, University of California, Irvine, Irvine, California \\ JyH-WEN HwU AND MONG-Ming LU \\ Center for Research and Development, Central Weather Bureau, Taipei, Taiwan \\ TAO GAO \\ Department of Earth System Science, University of California, Irvine, Irvine, California, and Inner Mongolia \\ Meteorological Institute, Hohhot, China
}

(Manuscript received 5 December 2014, in final form 19 February 2015)

\begin{abstract}
This study reveals a possible cause of model bias in simulating the western Pacific subtropical high (WPSH) variability via an examination of an Atmospheric Model Intercomparison Project (AMIP) simulation produced by the atmospheric general circulation model (AGCM) developed at Taiwan's Central Weather Bureau (CWB). During boreal summer, the model overestimates the quasi-biennial (2-3 yr) band of WPSH variability but underestimates the low-frequency (3-5 yr) band of variability. The overestimation of the quasibiennial WPSH sensitivity is found to be due to the model's stronger sensitivity to the central Pacific El NiñoSouthern Oscillation (CP ENSO) that has a leading periodicity in the quasi-biennial band. The model underestimates the low-frequency WPSH variability because of its weaker sensitivity to the eastern Pacific (EP) ENSO that has a leading periodicity in the 3-5-yr band. These different model sensitivities are shown to be related to the relative strengths of the mean Hadley and Walker circulations simulated in the model. An overly strong Hadley circulation causes the CWB AGCM to be overly sensitive to the CP ENSO, while an overly weak Walker circulation results in a weak sensitivity to the EP ENSO. The relative strengths of the simulated mean Hadley and Walker circulations are critical to a realistic simulation of the summer WPSH variability in AGCMs. This conclusion is further supported using AMIP simulations produced by three other AGCMs, including the CanAM4, GISS-E2-R, and IPSL-CM5A-MR models.
\end{abstract}

\section{Introduction}

Sea level pressure (SLP) is one of fundamental atmospheric variables describing the distribution of the air mass and the circulations it induces. Over the North Pacific, the SLP climatology is characterized by two major features: an Aleutian low over the high-latitude Pacific and a Pacific subtropical high over the eastern Pacific. In boreal summer, the Pacific subtropical high expands and occupies a large portion of the North Pacific and becomes the dominant SLP feature. The

\footnotetext{
Corresponding author address: Dr. Houk Paek, Department of Earth System Science, University of California, Irvine, Irvine, CA 92697-3100.

E-mail: paekh@uci.edu
}

western flank of the subtropical high is referred to as the western Pacific subtropical high (WPSH) and is known to have profound impacts on Asian-Pacific climate. Variations in the location and intensity of the WPSH, for example, are known to affect the East Asian summer monsoon strength (e.g., Chang et al. 2000; Wang et al. 2000; Lee et al. 2005) and the western Pacific typhoon track (e.g., Ho et al. 2004; Wu et al. 2005). Therefore, it is important for a general circulation model (GCM) to realistically simulate the WPSH variability to be useful for weather forecasts and climate projections for the Asian-Pacific region.

A major source of the WPSH variability comes from the atmospheric response to the forcing from El NiñoSouthern Oscillation (ENSO). It is known that the intensity of the WPSH tends to increase in the summer 
following an El Niño event (e.g., Wang et al. 2000; Kumar and Hoerling 2003; Sui et al. 2007; Xie et al. 2009). ENSO events have been suggested to induce sea surface temperature (SST) anomalies near the WPSH region to sustain the WPSH variability through local air-sea interactions (Wang et al. 2000), or to induce SST anomalies in the Indian Ocean and around the Maritime Continent region that later excite atmospheric wave motions to maintain the WPSH variability (Xie et al. 2009).

These views on WPSH-ENSO relations were developed based on a conventional view of ENSO in which events onset near the South American coast and later extend from the eastern to central equatorial Pacific. It has been increasingly recognized that there exists at least one more type of ENSO that onsets, develops, and decays locally in the equatorial central Pacific (Larkin and Harrison 2005; Yu and Kao 2007; Ashok et al. 2007; Kao and Yu 2009; Kug et al. 2009). This type of ENSO is often referred to as the central Pacific (CP) ENSO, while the conventional type of ENSO is referred to as the eastern Pacific (EP) ENSO. These two terms were introduced by $\mathrm{Yu}$ and Kao (2007) and Kao and Yu (2009) to emphasize the different longitudinal locations of these types of ENSO. Many studies have revealed that the CP ENSO can affect global and regional climate differently from the EP ENSO (e.g., Larkin and Harrison 2005; Hu et al. 2012; Yu et al. 2012b). The CP ENSO has occurred more frequently in the past few decades (Ashok et al. 2007; Kao and Yu 2009; Kug et al. 2009). The intensity of El Niño in the central Pacific region, for example, has doubled in the past three decades (Lee and McPhaden 2010), and the El Niño events in the twenty-first century so far have been mostly of the CP type (Yu et al. 2012b). Therefore, the effects of ENSO on the WPSH variability need to be considered separately for the two types.

Two recent studies suggested that the time that the ENSO type changes from being predominantly of the EP type to being predominately of the CP type is around the early 1990s (Yu et al. 2012a, 2015). It is very interesting to note that summer WPSH variability also exhibits changes around this time. Sui et al. (2007) noticed that the periodicity of the WPSH variability changed from being centered on a 3-5-yr band before the early 1990s to being centered on a 2-3-yr band afterward. They suggested that the 3-5-yr band is connected to eastern Pacific SST variations through the Walker circulation (WC) and the 2-3-yr band is connected to SST variations around the Maritime Continent through the Hadley circulation (HC). Their results indicate that the different modes of WPSH variability are related to the SST variations in different regions of the tropical Pacific. In Park et al. (2010), an empirical orthogonal function (EOF) analysis of the $850-\mathrm{hPa}$ winds anomalies was performed to identify the leading modes of
WPSH variability. They also noticed that the leading mode of WPSH variability changed around the early 1990s. The leading EOF mode before the early 1990s was found to be dominated by a 4-5-yr periodicity and associated with an SST anomaly pattern resembling the EP ENSO. The leading mode of WPSH variability after the early 1990s was found to be dominated by a 2-3-yr periodicity and associated with SST anomalies resembling the CP ENSO. These recent studies together suggest that there exist two distinct modes of summer WPSH variability, which are separately related to the two types of ENSO. The leading mode of WPSH variability changed in the early 1990s when the dominant type of ENSO changed.

It is reasonable to hypothesize that an atmospheric general circulation model (AGCM) needs to realistically simulate the separate relationships between the two WPSH modes and the two ENSO types in order to produce a realistic simulation of the WPSH variability. In other words, an AGCM's bias in the simulation of WPSH variability may arise from the model's inability to realistically simulate the different WPSH responses to the forcing from the two types of ENSO. This study uses an Atmospheric Model Intercomparison Project (AMIP; Gates et al. 1999) type of simulation produced by an AGCM to examine this hypothesis. We contrast the simulated and observed relationships between the WPSH variability and the two types of ENSO to understand why an AGCM can or cannot realistically simulate the WPSH relationships with the two types of ENSO. We choose to use in this study the AGCM developed by the Central Weather Bureau (CWB) of Taiwan. This AGCM is chosen because it has been particularly developed for weather and climate prediction in the AsianPacific region. Findings obtained from the analysis of this particular AGCM are verified with the AMIP simulations from three other AGCMs: the CanAM4, GISS-E2-R, and IPSL-CM5A-MR models. Therefore, the results reported here are not only specific to the CWB AGCM but also applicable to other climate models.

This paper is organized as follows. Section 2 describes the data used for a model diagnosis. Section 3 briefly documents the configurations of the CWB AGCM. Section 4 discusses the WPSH climatology and interannual variability. Section 5 uses two model sensitivity experiments to confirm the findings obtained from the AMIP simulation. Section 6 investigates the possible causes of the model deficiency. Section 7 verifies the findings obtained with the CWB AGCM using AMIP simulations from the other three AGCMs. A summary is given in section 8 .

\section{Data}

In this study, a 58-yr (1949-2006) AMIP simulation produced by the CWB AGCM is used. The simulation 
TABLE 1. Three CMIP5-AMIP models used in this study.

\begin{tabular}{llll}
\hline \hline Model name & & Modeling group & Horizontal resolution \\
\hline 1 & CanAM4 & Canadian Centre for Climate Modeling and Analysis (CCCMA) & $2.8^{\circ} \times 2.8^{\circ}$ \\
2 & GISS-E2-R & NASA Goddard Institute for Space Studies (NASA GISS) & $2.5^{\circ} \times 2.0^{\circ}$ \\
3 & IPSL-CM5A-MR & L'Institut Pierre-Simon Laplace (IPSL) & $2.5^{\circ} \times 1.25^{\circ}$ \\
\hline
\end{tabular}

was conducted following the AMIP protocol (Gleckler 2004), where the SST and sea ice boundary conditions used for the AMIP simulation are provided by the Program for Climate Model Diagnosis and Intercomparison (PCMDI; http://www-pcmdi.llnl.gov/projects/ amip/index.php). To verify the findings obtained using the CWB model, we also use AMIP simulations from another three AGCMs from the fifth phase of the Coupled Model Intercomparison Project (CMIP5; Taylor et al. 2012; available online at http://pcmdi9.1lnl.gov/) for the period 1949-2006 as summarized in Table 1. Monthly values of SLPs and meridional and vertical (omega) winds are analyzed in this study. Monthly anomalies are obtained by removing the seasonal cycles. For the observations, we use the monthly SLPs and winds from the National Centers for Environmental Prediction-National Center for Atmospheric Research (NCEP-NCAR) reanalysis (Kalnay et al. 1996; available online at www.esrl.noaa.gov/ $\mathrm{psd} /$ ) and SSTs from the Hadley Centre Sea Ice and Sea Surface Temperature dataset (HadISST; Rayner et al. 2003; available online at www.metoffice.gov.uk/hadobs/hadisst/).

\section{Overview of the CWB AGCM}

The basic features of the CWB AGCM are similar to those of the earlier version of the AGCM (hereafter AGCMg2), which is described in Liou et al. (1997). Several changes have been made since the AGCMg2 was made operational in January 1995. The spectral formulation for representation of the horizontal variation of prognostic variables of the current model is the same as the AGCMg2 except that the horizontal resolution was increased from a spectral triangular truncation of 79 waves (T79) (equivalent to approximately a $166-\mathrm{km}$ grid resolution) to T119 $(\sim 111 \mathrm{~km})$, the number of vertical sigma levels was increased from 18 to 40 , and the model top was elevated from 10 to $1 \mathrm{hPa}$.

The parameterizations of physical processes have been substantially revised to match those used in the NCEP Climate Forecast System version 2 (CFSv2; Saha et al. 2014). The surface fluxes are calculated based on Miyakoda and Sirutis (1986). The atmospheric boundary layer is calculated based on the simple model of Troen and Mahrt (1986). The land surface scheme used is the four-layer Noah scheme (Ek et al. 2003). Radiative transfer is calculated following Fu and Liou $(1992,1993)$ and Fu et al. (1997). Cumulus convection is parameterized by a relaxed Arakawa-Schubert (RAS) parameterization scheme (Moorthi and Suarez 1992). The large-scale precipitation is calculated using the Zhao and Carr (1997) scheme and shallow convection is parameterized using the scheme of $\mathrm{Li}$ (1994). Gravity wave drag effects are calculated using Palmer et al. (1986).

\section{WPSH climatology and variability in boreal summer}

We first compare in Fig. 1 the summer [June-JulyAugust (JJA)] SLP climatology produced by the CWB
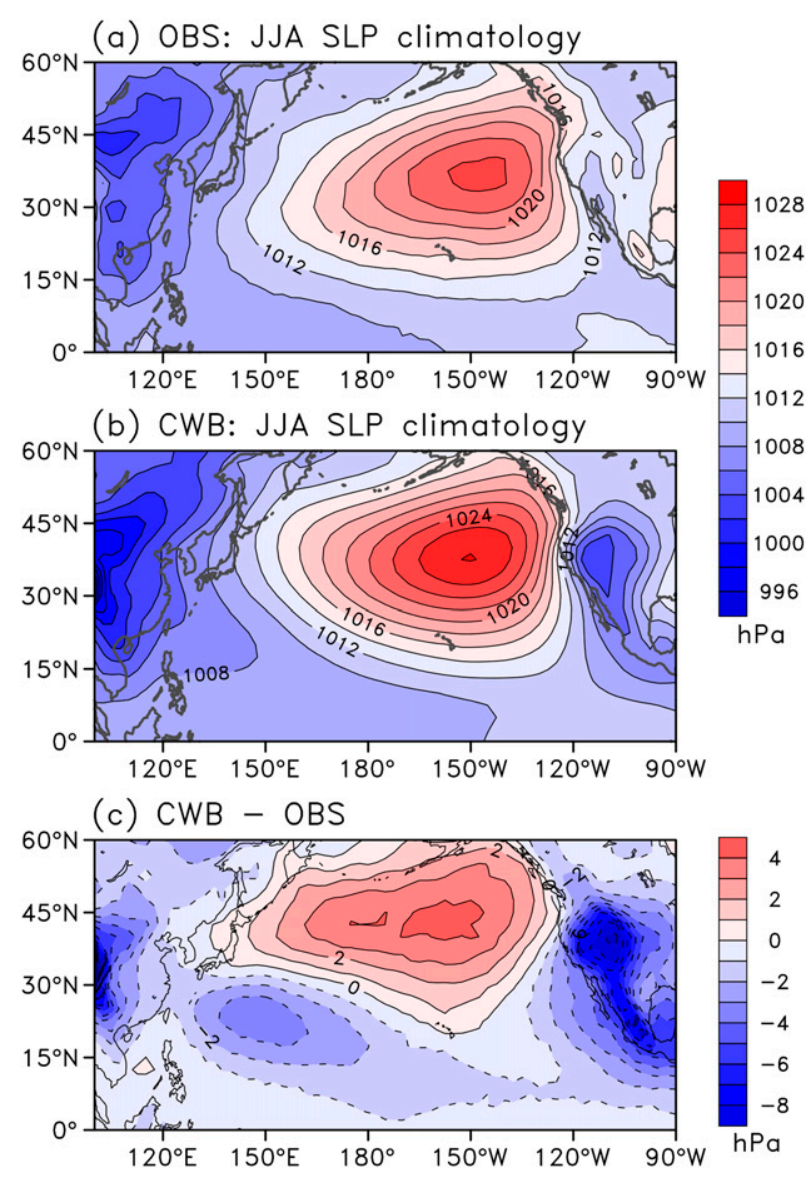

FIG. 1. (a) SLP climatology for the summer (JJA) calculated from observations. The contour interval is $2 \mathrm{hPa}$. (b) As in (a), but for the CWB AGCM simulation. (c) The SLP differences between the model simulation and observations. Solid (dashed) contours indicate positive (negative) values with an interval of $1 \mathrm{hPa}$. 
(a) OBS: std. SLP \& COR(WPSH,SLPA)

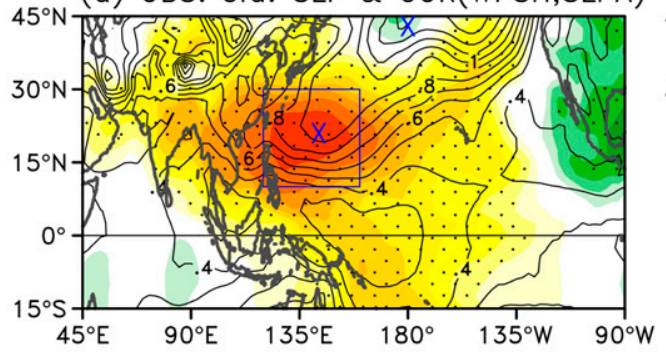

(c) OBS: WPSH Index

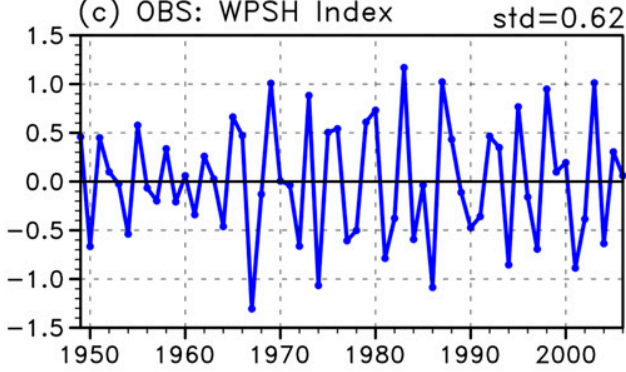

(e) OBS: Power Spectrum

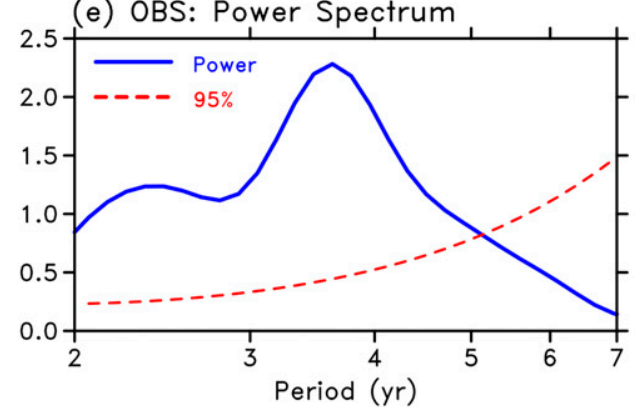

(b) CWB: std. SLP \& COR(WPSH,SLPA)

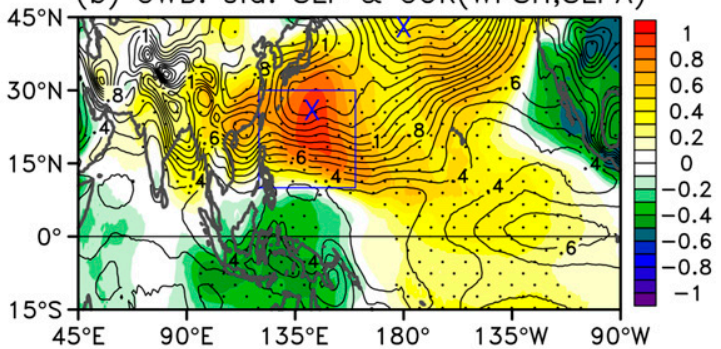

(d) CWB: WPSH Index

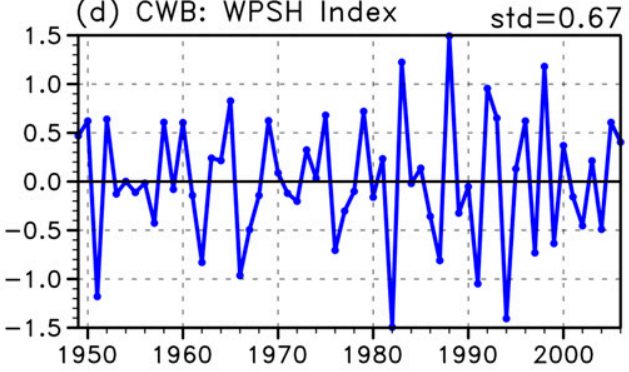

(f) CWB: Power Spectrum

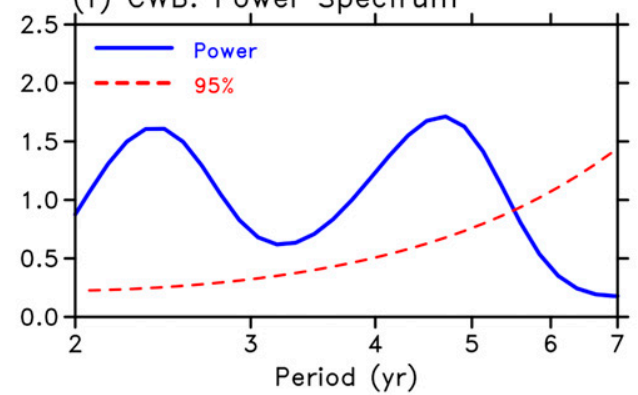

FIG. 2. (a) The standard deviations (contours) of the JJA SLP anomalies (2-7 yr filtered) and the correlation coefficients (shading) between the WPSH index and SLP anomalies (2-7 yr filtered) for the observations. The contour interval is $0.1 \mathrm{hPa}$. The correlation coefficients exceeding the $95 \%$ confidence interval using a two-tailed Student's $t$ test are dotted. The crisscrosses indicate the local maxima in the northeastern and northwestern Pacific, respectively. The blue box indicates the region used to define the WPSH index. (b) As in (a), but for the CWB AGCM simulation. (c) The time series of the WPSH index (hPa) for the observations. (d) As in (c), but for the simulation. (e) The power spectrum (blue line) of the standardized WPSH index for the observations. The red dashed line represents the $95 \%$ significance level. (f) As in (e), but for the simulation.

AGCM over the North Pacific with the observed climatology calculated from the NCEP-NCAR reanalysis. The simulated subtropical high (Fig. 1b) is in general close to the observed one (Fig. 1a), both of which extend from the northeastern Pacific to the northwestern Pacific outside the Asian continent. Some discrepancies exist between the simulation and the observations as can be seen by their differences in Fig. 1c. The simulated high tends to be too strong in the eastern Pacific and to be too zonally extended compared with the observed high. Model biases also occur over East Asia and North America, which neighbor the subtropical high. Additionally, a negative bias is also found in the western Pacific, where the WPSH is located (broadly over $10^{\circ}-30^{\circ} \mathrm{N}, 100^{\circ}$ $160^{\circ} \mathrm{E}$ ). This means that the simulated WPSH strength is underestimated during boreal summer. The largest SLP differences in the WPSH region are about $3 \mathrm{hPa}$, which is not particularly large.

We examine in Fig. 2 the interannual $(2-7 \mathrm{yr})$ variability of the summer SLP in the WPSH region. The bandpass filter used in this study is the fourth-order Butterworth filter (Parks and Burrus 1987) that is commonly used in climate analysis. Two local maxima can be identified in the observed variability (contours in Fig. 2a): one located in the northeastern Pacific and the other in the northwestern Pacific (indicated by the crisscrosses in the figure). The former coincides with the summer center of the Pacific subtropical high (see Fig. 1a), while the latter is in the region where the WPSH typically locates. The CWB AGCM (Fig. 2b) 

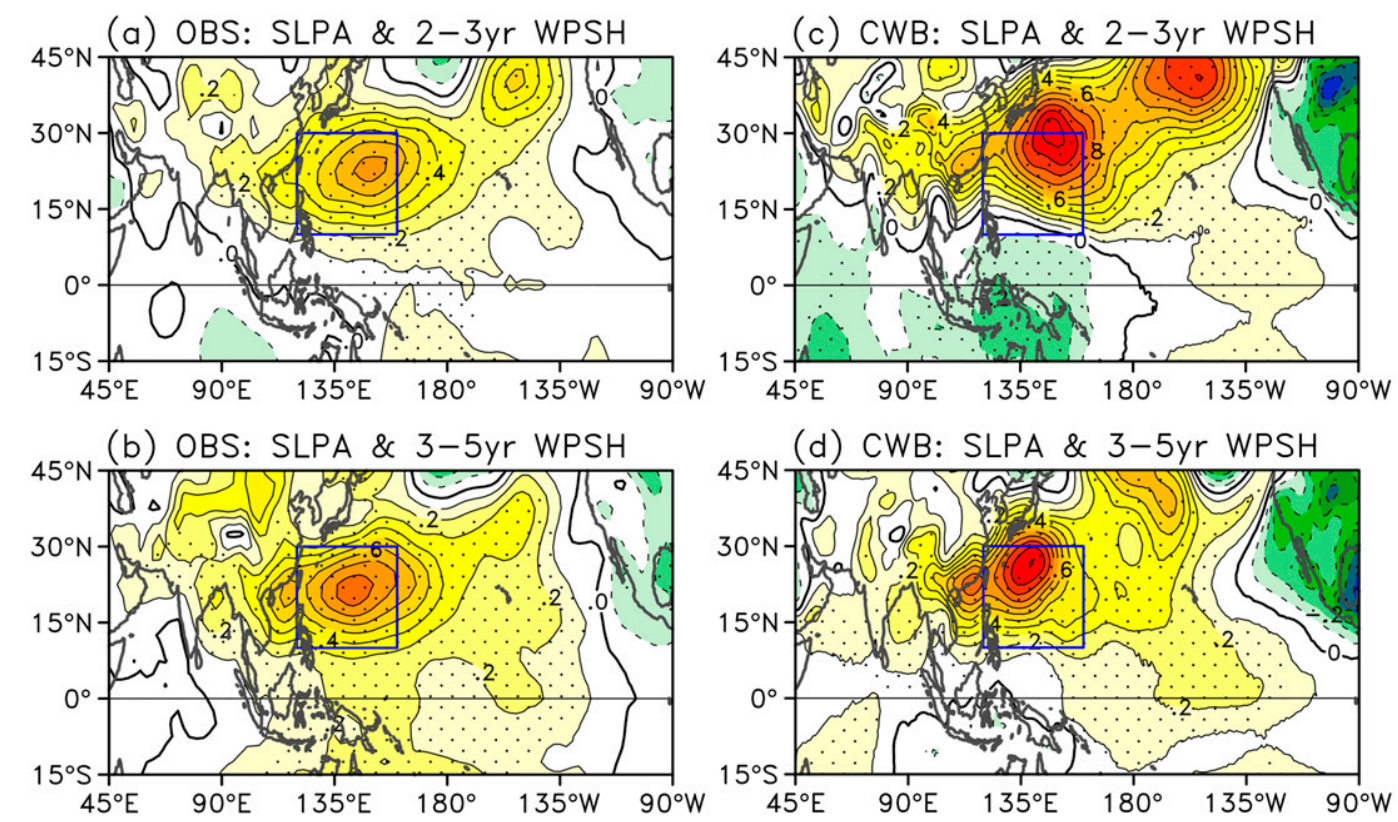

FIG. 3. (a) The regressed JJA SLP anomalies onto the 2-3-yr filtered JJA WPSH index from the observations. Solid (dashed) contours indicate positive (negative) values with an interval of $1 \mathrm{hPa}$. The regression coefficients exceeding the 95\% confidence interval using a two-tailed Student's $t$ test are dotted. The blue box indicates the WPSH region. (b) As in (a), but for the 3-5-yr filtered JJA WPSH index. (c),(d) As in (a),(b), respectively, but for the CWB AGCM simulation.

reproduces the maximum SLP variability in these two centers. Additionally, the model also produces a local maximum over the tropical eastern Pacific, which is less obvious in the observations. To reveal the exact spatial pattern of the WPSH variability, we first construct a WPSH index by averaging the SLP anomalies (2-7 yr filtered) inside a region $\left(10^{\circ}-30^{\circ} \mathrm{N}, 120^{\circ}-160^{\circ} \mathrm{E}\right.$; outlined by blue box in Fig. 2a) that covers the local maximum center of the standard deviations in the northwestern Pacific. The region we selected to define the WPSH index is similar to the WPSH regions used by other studies (e.g., Sui et al. 2007; Wang et al. 2013). We then correlate Pacific SLP anomalies (2-7 yr filtered) with our WPSH index. The correlation coefficients in Fig. 2a (shading) indicate that the observed WPSH variability pattern spans a region from the coast of the Asian continent to the international date line and has a center near $20^{\circ} \mathrm{N}$, $140^{\circ} \mathrm{E}$. We repeat the procedure with the CWB AGCM's AMIP simulation and find that the simulated WPSH variability (Fig. 2b) has a spatial pattern and magnitude reasonably close to the observed one. However, the simulated WPSH pattern has a strong negative correlation with the interannual SLP variability in the tropical western Pacific (over the Maritime Continent), which does not appear in the observations.

As mentioned, previous studies have indicated that the WPSH variability is associated with the ascending motions induced by positive SST anomalies over the equatorial eastern Pacific and the Indian Ocean in the 35-yr band, and with the ascending motions induced by positive SST anomalies over the Maritime Continent in the 2-3-yr band (Sui et al. 2007; Chung et al. 2011). Based on this information, it is likely that the unrealistic dipole-like correlation pattern of the simulated WPSH variability in the CWB AGCM is a reflection of an overestimation of the $2-3-y r$ band. To examine this possibility, we plot in Figs. $2 \mathrm{c}$ and $2 \mathrm{~d}$ the time series of the observed and simulated WPSH indices. The standard deviations of these two time series are found to be similar: $0.62 \mathrm{hPa}$ for the observations and $0.67 \mathrm{hPa}$ for the simulation. A power spectrum analysis shows that the observed WPSH index (Fig. 2e) has larger power in the $3-5$-yr band than in the 2-3-yr band, whereas the simulated WPSH index (Fig. 2f) has power in the 2-3-yr band as large as that in the 3-5-yr band. Apparently, a relatively too strong 2-3-yr band and a relatively too weak $3-5$-yr band are the major model biases of the CWB AGCM in its simulation of the summer WPSH.

Why then are the power in the 2-3-yr band of the WPSH overestimated and the power in the 3-5-yr band underestimated in the AGCM? To answer these questions, we separate the $2-3-\mathrm{yr}$ and $3-5-\mathrm{yr}$ bands in the observed and simulated WPSH indices. The filtered indices are then used to examine the associated SLP and SST anomaly structures of these two bands of WPSH variability. Figures $3 a$ and $3 b$ show the SLP anomaly 
patterns regressed onto the two bands of the observed WPSH index in JJA. These two regression patterns are different in their northeastward extension structures. For the 2-3-yr band (Fig. 3a), there are two separate centers with comparable magnitudes (i.e., 0.7 and 0.5 in regression coefficients, respectively). In contrast, the $3-$ 5-yr band (Fig. 3b) has a single major center over the northwestern Pacific, and a small secondary center in the northeastern Pacific that is relatively weak. The regression coefficient is 0.8 for the northwestern Pacific center but only 0.3 for the northeastern Pacific center. The same regression analysis applied to the AMIP simulation reveals that the modeled SLP patterns in both the 2-3-yr (Fig. 3c) and 3-5-yr (Fig. 3d) bands are close to the observed pattern in the $2-3-y r$ band. This analysis indicates that the CWB AGCM produces the observed 2-3-yr band of WPSH variability but not the observed 3-5-yr band of WPSH variability.

Figure 4 shows the correlation coefficients between the JJA WPSH index in the 2-3-yr band and the seasonal SST anomalies in the previous (year -1) and current (year 0) years. Since the WPSH intensity tends to increase in the summer following an El Niño event, $\mathrm{JJA}(-1)$ and $\mathrm{JJA}(0)$ in this study are referring to the summer before and after the peak phase of El Niño, respectively. In the observations, the correlated SST anomalies for the 2-3-yr band (Fig. 4a) resemble more the spatial structure and temporal evolution of the $\mathrm{CP}$ El Niño than the EP El Niño. As described in Kao and $\mathrm{Yu}$ (2009), a typical CP El Niño event is often preceded by positive SST anomalies in the eastern subtropical Pacific in the spring of the El Niño year [e.g., (March-May) $\operatorname{MAM}(-1)$ in Fig. 4a]. These positive anomalies persist to the following seasons [(June-August) JJA $(-1)$, (September-November) SON $(-1)]$ and penetrate into the equatorial central Pacific around the date line. The anomalies in the central Pacific then spread eastward reaching a peak phase in winter [(December-February) $\mathrm{D}(-1) \mathrm{JF}(0)]$ and decay in the central Pacific in the following seasons $[\mathrm{MAM}(0), \mathrm{JJA}(0)]$. This sequence of the CP El Niño SST evolution is close to what is shown in Fig. 4a. This similarity confirms that the 2-3-yr band of the observed WPSH variability is related to the CP ENSO forcing. The 2-3-yr band discussed here is similar to the EOF-2 mode discussed in Wang et al. (2013, see their Fig. 3a). They suggested that the EOF-2 mode of WPSH variability is a result of a Gill-type Rossby wave response to SST anomalies in the central Pacific. In the CWB AGCM simulation, the 2-3-yr band of WPSH variability is also associated with SST anomalies characteristic of the CP El Niño, with positive SST anomalies developing in spring (top panels of Fig. 4b), peaking in winter (middle panels), and decaying rapidly afterward (bottom panels). Although there are indications in the simulation (as well as in the observations) that positive SST anomalies also appear in the eastern Pacific, they tend to be weaker than those in the central Pacific. Overall, the results shown in Fig. 4 indicate that the CWB AGCM is responsive to the SST forcing from the CP ENSO that gives rise to the $2-3-y r$ band of WPSH variability.

As for the 3-5-yr band of WPSH variability, the correlated SST anomalies in the observations (Fig. 5a) are confined more to the eastern Pacific and South American coast and resemble the spatial structure and temporal evolution of the EP El Niño. Positive SST anomalies develop near the equatorial coast of South America and spread westward to the central Pacific during the fall and winter $[\mathrm{SON}(-1), \mathrm{D}(-1) \mathrm{JF}(0)]$. The positive anomalies persist into the spring and summer during the decaying ENSO phase $[\operatorname{MAM}(0), \operatorname{JJA}(0)]$ in the eastern Pacific, together with Indian Ocean warming in summer. The 3-5-yr band is similar to the EOF-1 mode of WPSH variability discussed by Wang et al. (2013, see their Fig. 2a). They suggested that this mode of WPSH variability is produced by the interactions between the WPSH and SST anomalies in the Indian and Pacific Oceans (i.e., an Indian Ocean warming and a Pacific cooling). A basinwide warming in the Indian Ocean is known to be forced by traditional EP El Niño events through an anomalous Walker circulation (e.g., Klein et al. 1999; Yu and Lau 2005; Xie et al. 2009; Kumar et al. 2014). Therefore, the 3-5-yr band of WPSH variability can be considered as a WPSH response to the forcing from the EP El Niño and the associated Indian Ocean warming.

In the CWB AGCM, the correlations of the 3-5-yr band with SST anomalies in the eastern Pacific (Fig. 5b) are not as strong as those observed. There is no strong indication of an EP ENSO occurring in the winter $[\mathrm{D}(-1) \mathrm{JF}(0)]$ preceding the summer WPSH variability. Instead, the correlated SST anomalies are dominated by La Niña-like conditions in the central Pacific during the concurrent summer [JJA(0)]. Also, the basinwide Indian Ocean warming emphasized by Wang et al. (2013) does not persist into the summer in the model simulation. These results indicate that the 3-5-yr band of WPSH variability in the CWB AGCM is forced by the SST variability in the tropical central Pacific. The model response to the tropical eastern Pacific SST variability is weaker than that found in the observations. It is our conclusion that the observed WPSH responds to the EP and CP ENSO forcing to produce, respectively, the 3-5and 2-3-yr bands of WPSH variability, but the CWB AGCM responds strongly only to the CP ENSO to produce both bands of WPSH variability. 
(a) OBS: SSTA \& 2-3yr WPSH
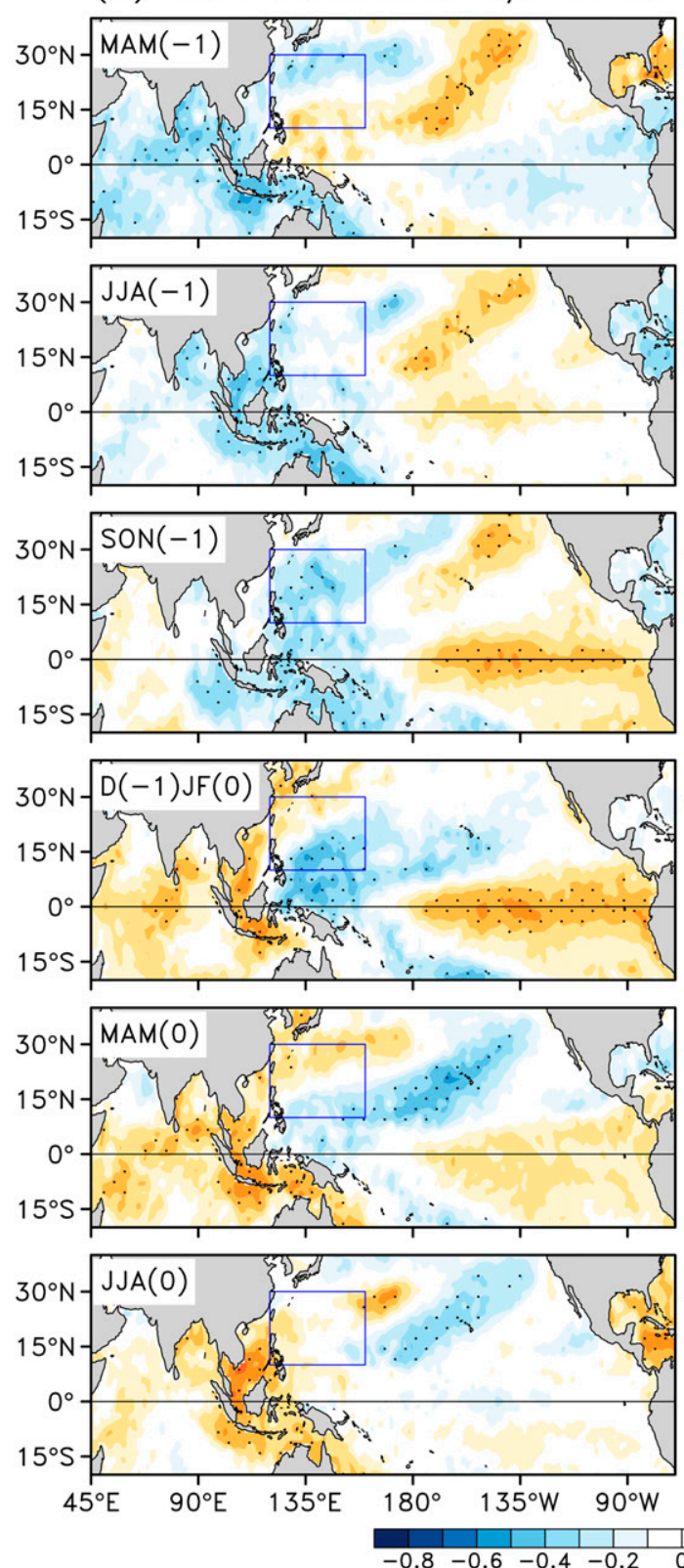

FIG. 4. (a) The lagged correlation coefficients between the 2-3-yr filtered JJA WPSH index and the seasonal SST anomalies in the previous and current years from the observations. The blue box indicates the WPSH region. The seasons and the years are indicated in the top-left corner of each panel. The -1 (0) represents the previous (current) year in the brackets. The area exceeding the $95 \%$ confidence interval using a two-tailed Student's $t$ test are dotted. (b) As in (a), but for the CWB AGCM simulation.

To further examine the associations between the two bands of WPSH variability and the two types of ENSO, we composite the SLP anomalies for the two types of ENSO events. According to Yu et al. (2012b), our analysis period includes 12 CP El Niño events (1953/54, 1957/58, 1958/59, 1963/64, 1965/66, 1968/69, 1977/78, 1987/88, 1991/92, 1994/95, 2002/03, and 2004/05) and 7 (b) CWB: SSTA \& 2-3yr WPSH
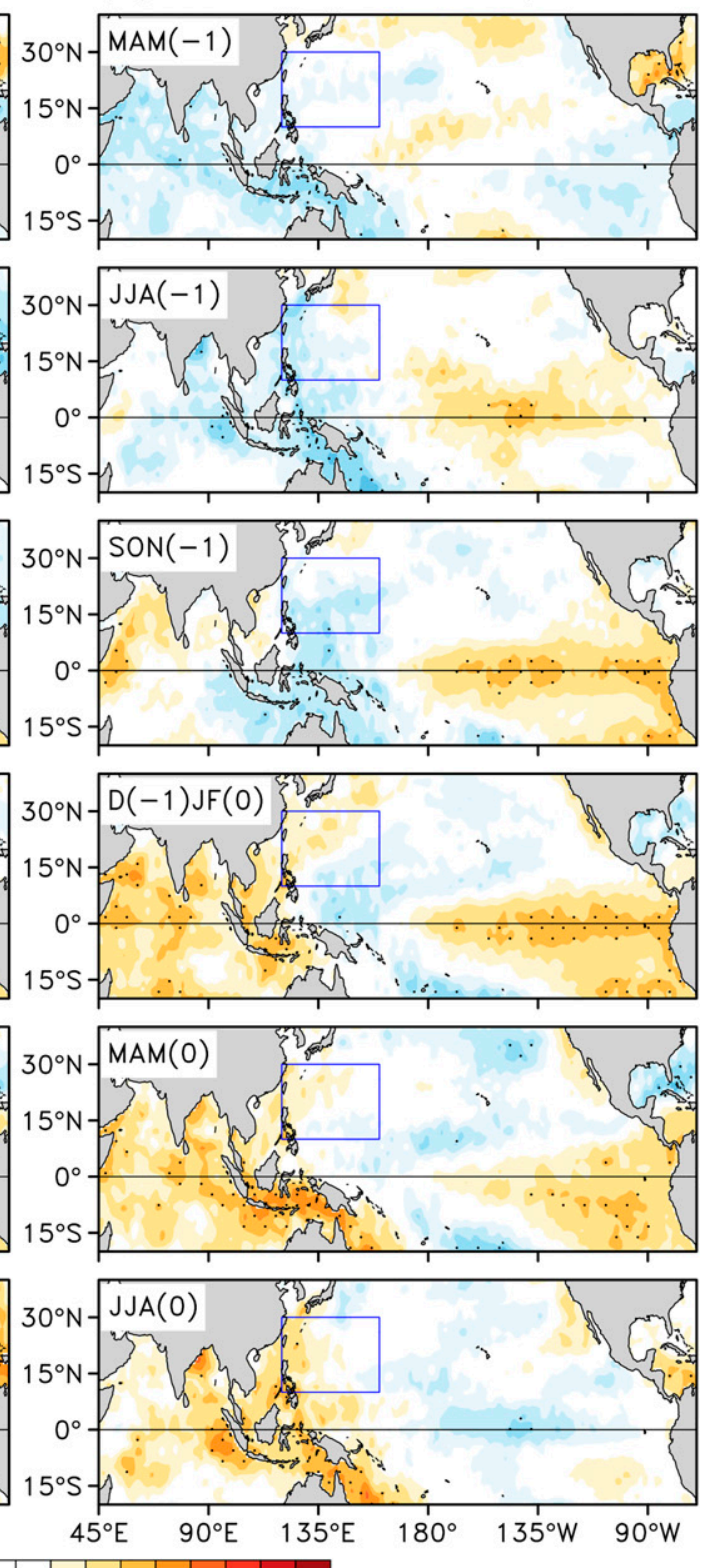

EP El Niño events (1951/52, 1969/70, 1972/73, 1976/77, 1982/83, 1986/87, and 1997/98). Figure 6 shows the composite SLP anomalies during the decaying summers [JJA(0)] of these two groups of El Niño events. During the CP El Niño (Fig. 6a), SLP anomalies are observed to intensify over the WPSH region and are accompanied by negative SLP anomalies over the Maritime 
(a) OBS: SSTA \& 3-5yr WPSH
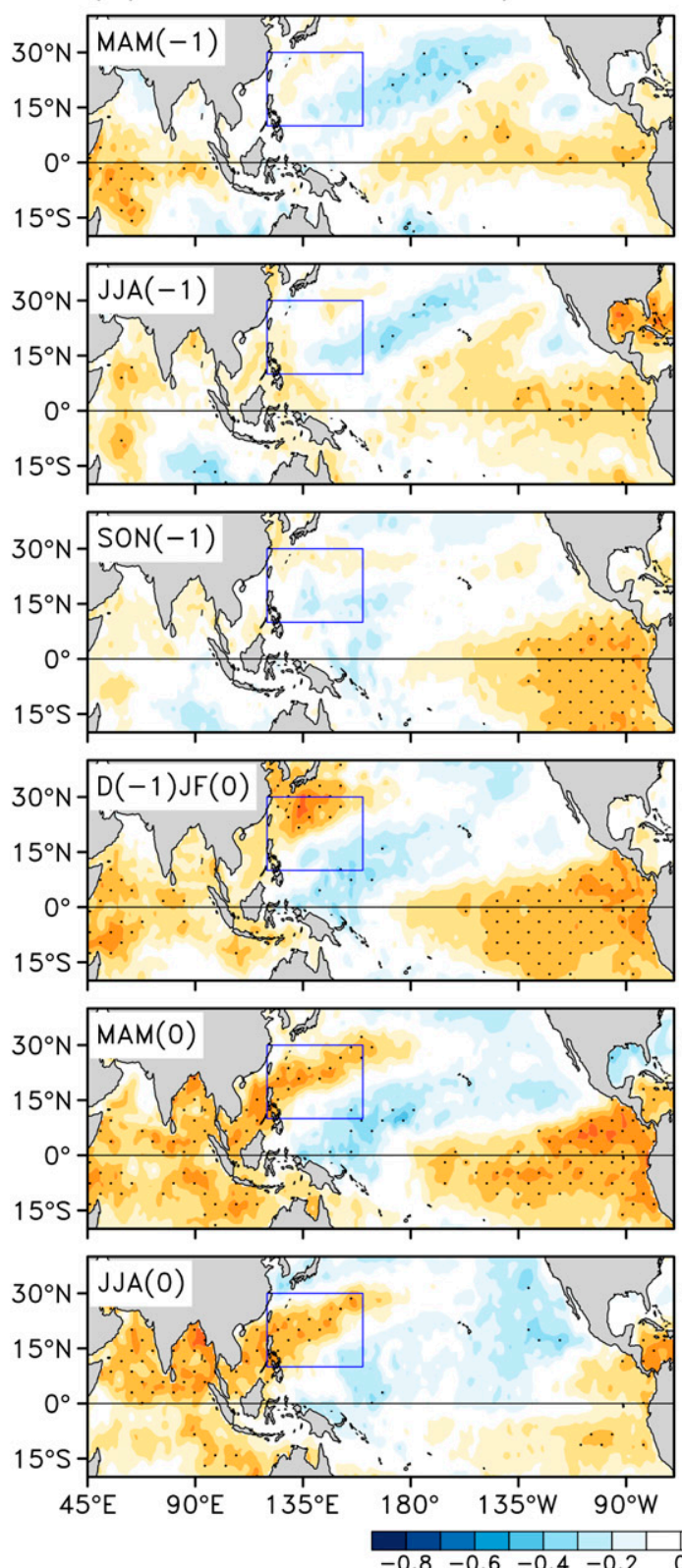

(b) CWB: SSTA \& 3-5yr WPSH
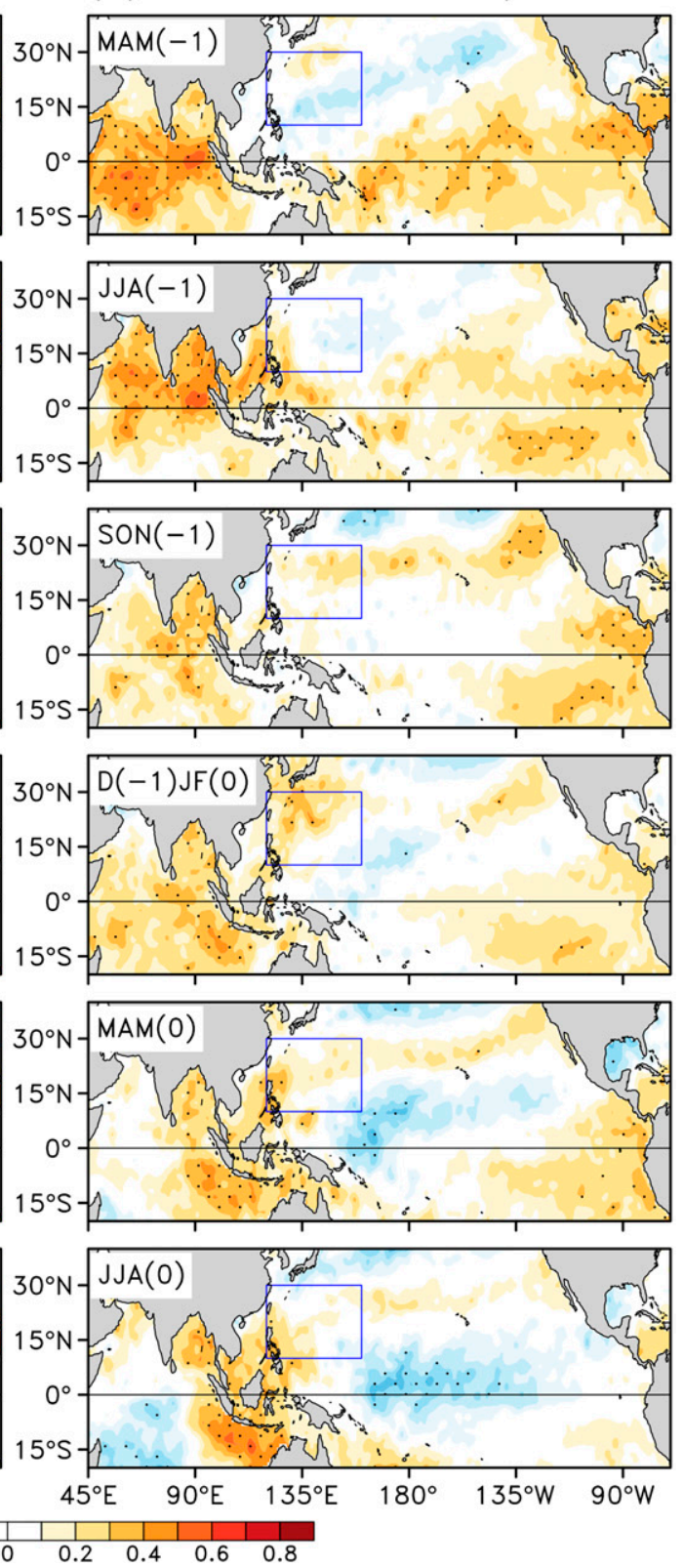

FIG. 5. (a),(b) As in Figs. 4a and 4b, respectively, but for the 3-5-yr filtered JJA WPSH indices.

Continent. The WPSH also intensified during the EP El Niño (Fig. 6b), but is not accompanied by negative SLP anomalies over the Maritime Continent. This difference over the Maritime Continent indicates that the WPSH variability composited for the $\mathrm{CP}$ El Niño events is similar to the 2-3-yr band of WPSH variability, while the variability composited for the EP El Niño events is similar to the 3-5-yr band of WPSH variability. The WPSH variability in the CP El Niño composite also shows a meridionally elongated structure similar to that of the 2-3-yr band of WPSH variability (cf. Fig. 3a), while the WPSH variability in the EP El Niño composite has a zonal elongation similar to that of the 3-5-yr band of WPSH variability (cf. Fig. 3b). It should be noted that the CP ENSO is known to have a leading periodicity of about two years and the EP ENSO has a leading periodicity of about four years (Kao and Yu 2009; Yu et al. 2010, 2011; Yu and Kim 2010). The leading periodicities of these two types of ENSO match the two bands of WPSH variability discussed here. 
(a) OBS: JJA SLPA \& DJF CP-EI Nino

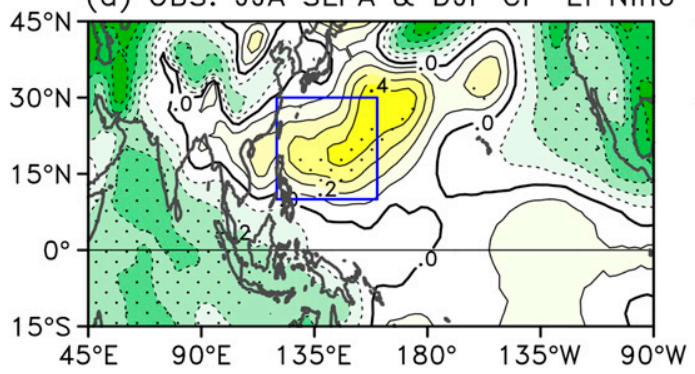

(b) OBS: JJA SLPA \& DJF EP-EI Nino

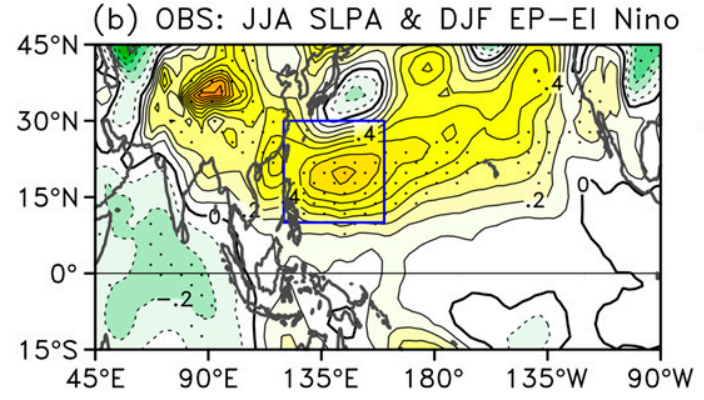

(c) CWB: JJA SLPA \& DJF CP-EI Nino

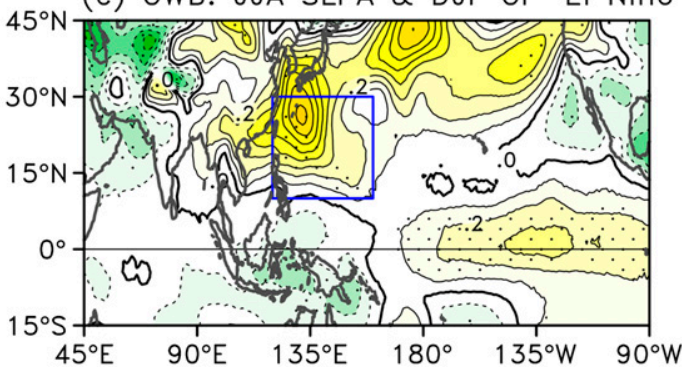

(d) CWB: JJA SLPA \& DJF EP-EI Nino

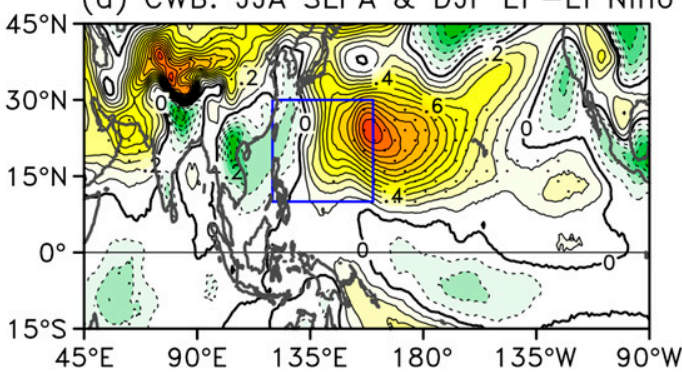

FIG. 6. (a) The composite SLP anomalies from the observations for the $12 \mathrm{CP}$ El Niño decaying summers [JJA(0)]. Solid (dashed) contours indicate positive (negative) values with an interval of $0.1 \mathrm{hPa}$. The SLP anomalies exceeding the $90 \%$ confidence interval using a two-tailed Student's $t$ test are dotted. The blue box indicates the WPSH region. (b) As in (a), but for the seven EP El Niño decaying summers. (c),(d) As in (a),(b), but for the simulation, respectively.

In the simulation, the SLP anomalies composited for the CP El Niño events are in general close to the observed composite (cf. Figs. 6c and 6a): positive anomalies are reproduced over the WPSH region and negative anomalies are reproduced over the Maritime Continent. However, the simulated SLP anomalies composited for the EP El Niño do not resemble the observed composite (cf. Figs. 6d and 6b). Positive SLP anomalies are produced only near the eastern edge of the WPSH region during the EP El Niño decaying summers. Unrealistic negative SLP anomalies are found over a large portion of the Asian continent and western half of the WPSH region. As a result of this erroneous SLP anomaly pattern, the anomaly value averaged within the WPSH box is much smaller in the simulation $(3.3 \mathrm{hPa})$ than in the observations $(5.0 \mathrm{hPa})$. The composite values for the $\mathrm{CP}$ El Niño are about the same for the simulation $(3.1 \mathrm{hPa})$ and the observations $(2.6 \mathrm{hPa})$. Therefore, the composite analysis according to the two types of ENSO further confirms that the CWB AGCM responds realistically in its WPSH simulation to the SST forcing from the CP El Niño, but underestimates the response to the forcing from the EP El Niño.

Based on the findings so far, we expect the simulated and observed WPSH indices to be less correlated before the early 1990s when the ENSO is dominated by the EP type but more correlated afterward when the ENSO became dominated by the CP type. It is encouraging to find that the correlation coefficient between the simulated and observed WPSH indices indeed increases from 0.44 for the period $1981-93$ to 0.70 for the period 1994-2006.

\section{Model sensitivity experiments}

As another effort to examine the findings from the AMIP simulation, we conducted two sensitivity experiments with the CWB AGCM. The experiments were designed as follows: a CP run in which the model is forced by SST anomalies characteristic of the peak phase of the CP type of El Niño and an EP run in which the model is forced by SST anomalies characteristic of the peak phase of the EP type of El Niño. The SST anomaly patterns were obtained using a regressionEOF analysis. As explained in Kao and Yu (2009) and Yu and Kim (2010), we first removed the SST anomalies regressed with the Niño-1+2 SST index (i.e., the EP ENSO influence) from the original monthly SST anomalies and then applied an EOF analysis to the residual SST anomalies to obtain the spatial pattern of the CP ENSO. Similarly, we subtracted the SST anomalies regressed with the Niño-4 index (i.e., the CP ENSO influence) from the original SST anomalies and then applied an EOF analysis to identify the leading structure of 

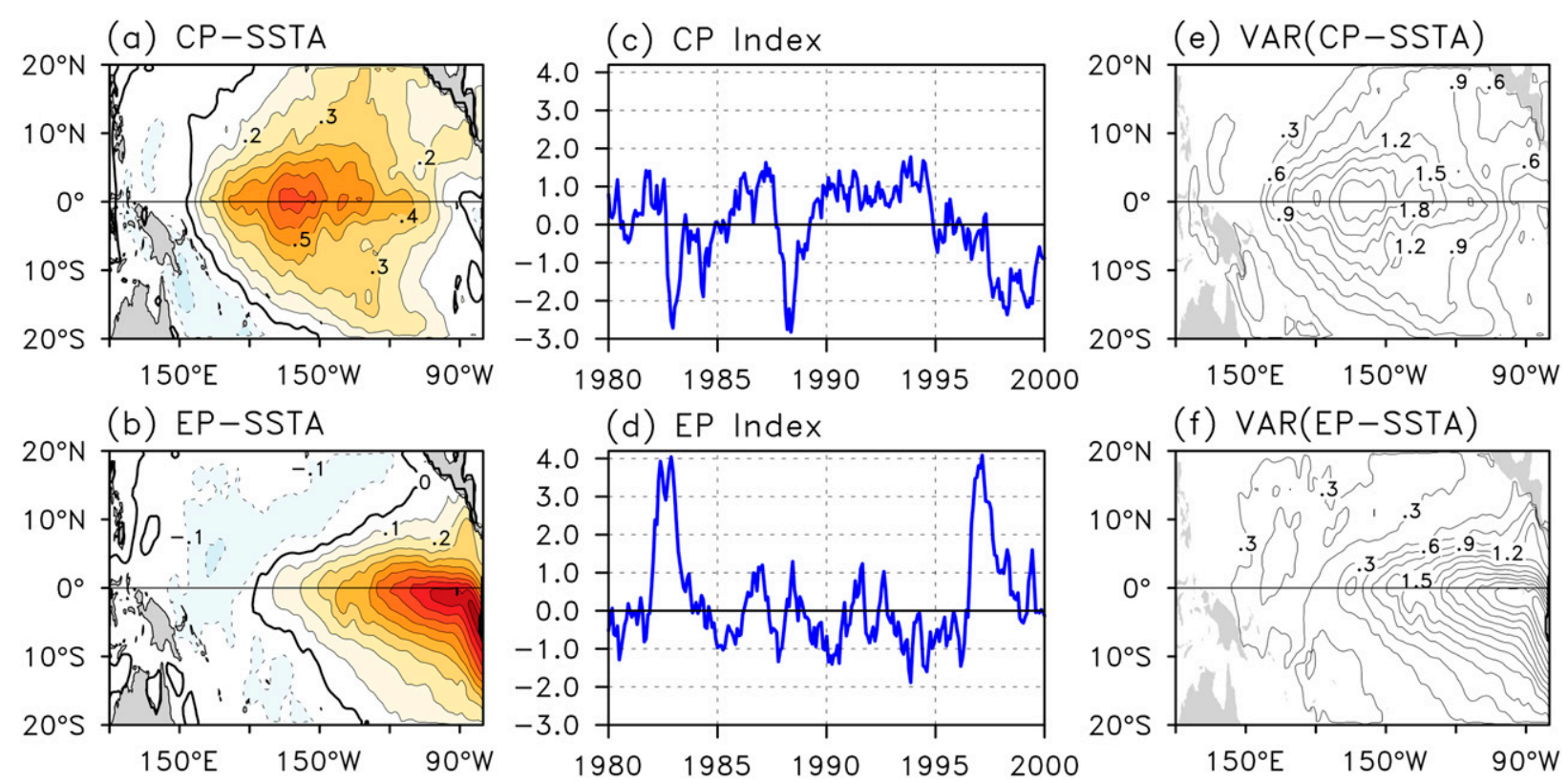

FIG. 7. (a) The SST anomaly pattern for the CP ENSO. Solid (dashed) contours indicate positive (negative) values with an interval of 0.1. (b) As in (a), but for the EP ENSO. (c) The time series of the CP index $\left({ }^{\circ} \mathrm{C}\right.$ ). (d) As in (c), but for the EP index. (e) The standard deviations of SST anomalies that force the CP run. The contour interval is $0.3^{\circ} \mathrm{C}$. (f) As in (e), but for the EP run.

the EP ENSO. Figures $7 \mathrm{a}$ and $7 \mathrm{~b}$ show the SST anomaly patterns obtained using this method and the HadISST dataset for an analysis period of 1980-2000. The CP ENSO (Fig. 7a) is characterized by positive SST anomalies with maximum values centered near the international date line and extending into the subtropics, while the EP ENSO (Fig. 7b) is characterized by SST anomalies with maximum values near the South American coast extending to the central Pacific along the equator. The principal components (PCs) associated with these patterns (shown in Figs. $7 \mathrm{c}$ and $7 \mathrm{~d}$ ) are referred to, respectively, as the $\mathrm{CP}$ index and EP index and represent the intensity evolutions of the CP ENSO and EP ENSO from 1980 to 2000 .

To construct the SST anomalies from 1980 to 2000 for the $\mathrm{CP}$ run, we multiplied the $\mathrm{CP}$ index (i.e., Fig. 7c) by the CP ENSO SST anomaly pattern (i.e., Fig. 7a) and by a factor of 3 . The factor of 3 is used to amplify the SST anomalies to values close to those observed during typical ENSO events. These anomalies were then added to the monthly SST climatology to force the CWB AGCM. Similarly for the EP run, we multiplied the EP index by the EP ENSO SST anomaly pattern and by a factor of 3 to construct the SST anomalies to drive the model. Only SST anomalies associated with the $\mathrm{CP}$ and EP ENSO in the tropical Pacific $\left(20^{\circ} \mathrm{S}-20^{\circ} \mathrm{N}, 120^{\circ} \mathrm{E}-80^{\circ} \mathrm{W}\right)$ are prescribed. Outside this region, the monthly SST climatology is used.
The model is integrated for the period 1980-2000 for each run. The standard deviations of the SST anomalies that force the CP and EP runs are shown in Figs. 7e and $7 \mathrm{f}$, which indicate that the maximum standard deviation is $2.1^{\circ} \mathrm{C}$ for the $\mathrm{CP}$ run and $3.1^{\circ} \mathrm{C}$ for the EP run. It should be noted that SST anomaly patterns are fixed in time in these experiments and do not include the SST anomaly evolution associated with the life cycle of the EP and CP ENSO (i.e., growth, peak, and decay). The experiments are meant to be a simple check of the WPSH sensitivity to the SST forcing in the CWB AGCM.

We first examine the WPSH variability produced in these two runs by calculating the standard deviations of SLP averaged in the WPSH box region. The standard deviation is $1.05 \mathrm{hPa}$ in the $\mathrm{CP}$ run and $0.92 \mathrm{hPa}$ in the EP run. The ratio of the WPSH variability in the CP run to the EP run is 1.14, which indicates that the $\mathrm{CP}$ run produces larger WPSH variability than the EP run, even though the maximum SST forcing in the EP run is slightly larger than that in the CP run (see the standard deviations shown in Figs. 7e and 7f). The sensitivity experiment result is consistent with the suggestion we made from the analysis of the CWB AMIP simulation: the CWB AGCM is more responsive (or sensitive) to the SST forcing from the CP region than from the EP region. We notice from Figs. $7 \mathrm{c}$ and $7 \mathrm{~d}$ that large negative values of CP ENSO index occur in the decaying years of EP ENSO events: 1982, 1987, and 1997. To exclude the 

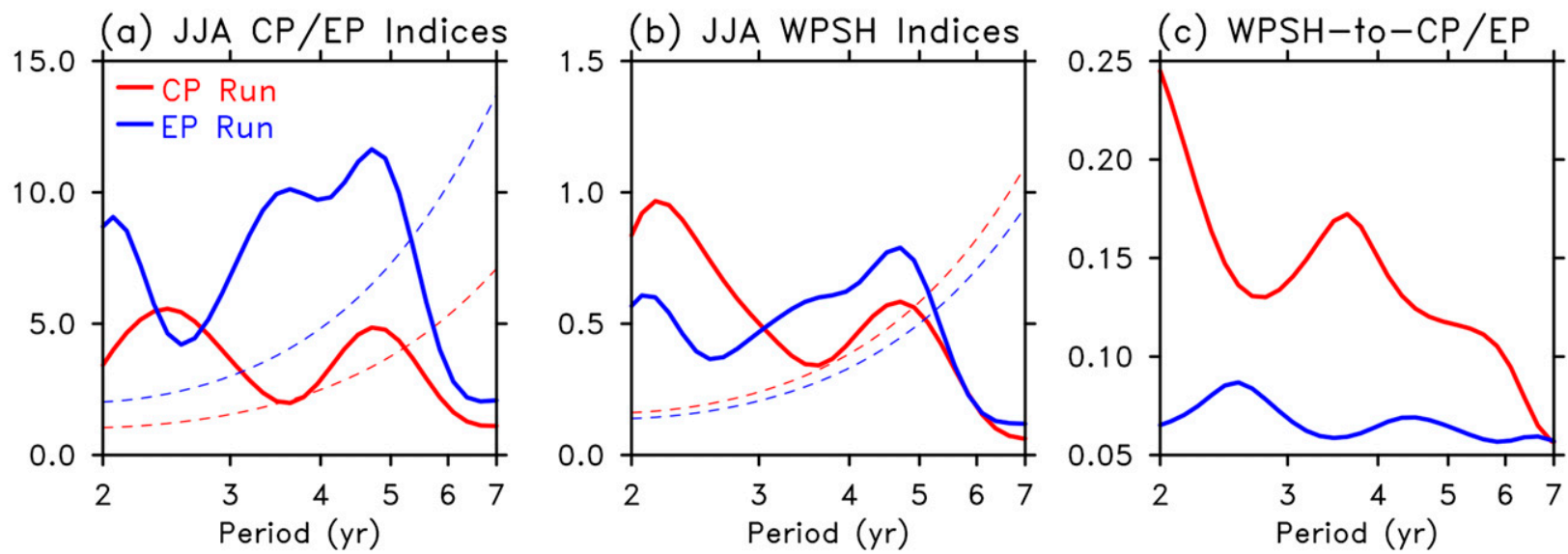

FIG. 8. (a) The power spectra of the CP index in the CP run (red line) and the EP index in the EP run (blue line). The red (blue) dashed line represents the $95 \%$ significance level for the CP (EP) run. The unit is ${ }^{\circ} \mathrm{C}^{2}$. (b) As in (a), but for the WPSH indices from the CP run (red line) and the EP run (blue line). The unit is $\mathrm{hPa}^{2}$. (c) The ratios of the power of the WPSH indices to the power of the CP index over each frequency in the CP run (red line), or to the power of the EP index in the EP run (blue line). The unit is $\mathrm{hPa}^{2}{ }^{\circ} \mathrm{C}^{-2}$.

possibility that the WPSH variability produced in the CP run may represent a response to the decaying EP ENSO events, we remove these three events from the EP and $\mathrm{CP}$ runs and recalculate the WPSH variability. We find the CP-to-EP ratio of the WPSH variability is still larger than one (i.e., 1.25).

Next we performed a power spectrum analysis on WPSH and SST indices from the CP and EP runs. Figure 8a shows the power spectra of the CP and EP indices (not bandpass filtered) that represent the temporal evolutions of the SST forcing prescribed for these two sensitivity experiments. As expected, the EP index (blue line) has the largest power in the 3-5-yr band, while the CP index (red line) has the largest power in the 2-3-yr band. Figure $8 \mathrm{~b}$ shows the power spectra of the WPSH indices calculated from these two experiments. The spectra indicate that the WPSH index in the CP run (red line) has the largest power in the 2-3-yr band, while the power spectrum in the EP run (blue line) has the largest power in the 3-5-yr band. The power spectra of the WPSH indices resemble those of the corresponding CP and EP indices. This similarity simply reflects the fact that the WPSH variability is responding to the prescribed tropical SST forcing. We then quantify the WPSH sensitivity to the SST forcing in these two runs by calculating the ratio of the power of the WPSH indices to that of the CP or EP indices over each frequency band. The ratios are shown in Fig. 8c. The figure indicates that the ratio is much larger in the CP run than that in the EP run over all frequency bands. Therefore, the results from these two 21-yr sensitivity experiments confirm that the CP SST forcing excites stronger WPSH variability than the EP SST forcing in the CWB AGCM.

\section{Possible causes for the different sensitivities to the CP and EP ENSO forcing in the CWB AGCM}

Here we explore the possible reason why the CWB AGCM is less responsive to the SST forcing in the tropical eastern Pacific. The 2-3-yr band of WPSH variability was suggested to be linked to the CP ENSO through the Hadley circulation and the 3-5-yr band of variability linked to the EP ENSO through the Walker circulation (e.g., Park et al. 2010). Yu et al. (2012a) also argued that the dominance of the two types of ENSO is related to the relative strengths of the mean Hadley and Walker circulations. It is possible that the model deficiency is related to how well the relative strengths of these two atmospheric circulations are simulated in the CWB AGCM. Following Oort and Yienger (1996), we use a WC index and an HC index to quantify the strengths of these two circulations. The HC strength is defined as the vertical shear of the meridional wind between 200 and $850 \mathrm{hPa}$ over the tropical Pacific $\left(10^{\circ} \mathrm{N}, 120^{\circ} \mathrm{E}-80^{\circ} \mathrm{W}\right)$, and the WC strength as the difference in $500-\mathrm{hPa}$ vertical wind between the eastern $\left(180^{\circ}-100^{\circ} \mathrm{W}\right)$ and western $\left(100^{\circ}-150^{\circ} \mathrm{E}\right)$ regions of the equatorial Pacific $\left(10^{\circ} \mathrm{S}-10^{\circ} \mathrm{N}\right)$. Figure 9 compares the
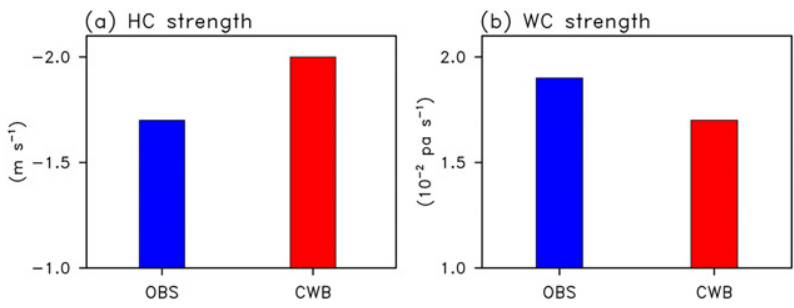

FIG. 9. (a) The JJA-mean Hadley circulation indices from observations (blue bar) and the CWB simulation (red bar). (b) As in (a), but for the Walker circulation. 
(a) CanAM4

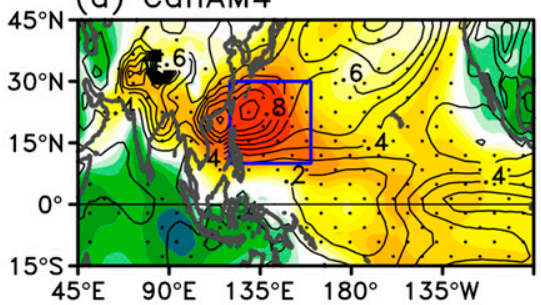

(d) CanAM4

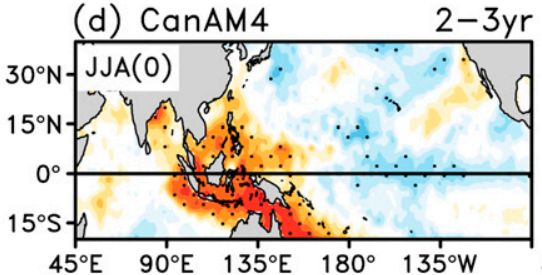

(g) CanAM4

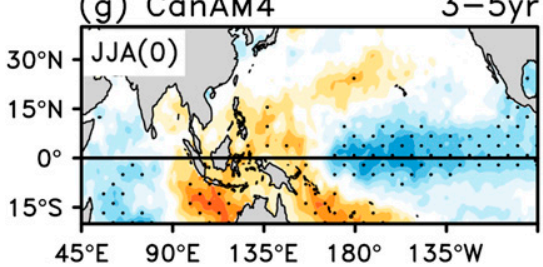

(b) GISS-E2-R

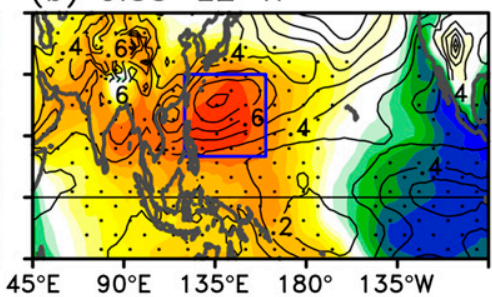

(c) IPSL-CM5A-MR

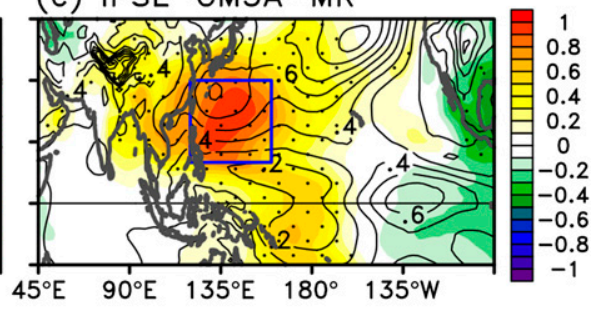

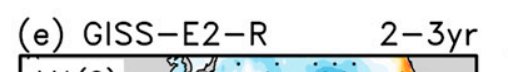

(f) IPSL-CM5A-MR 2-3yr
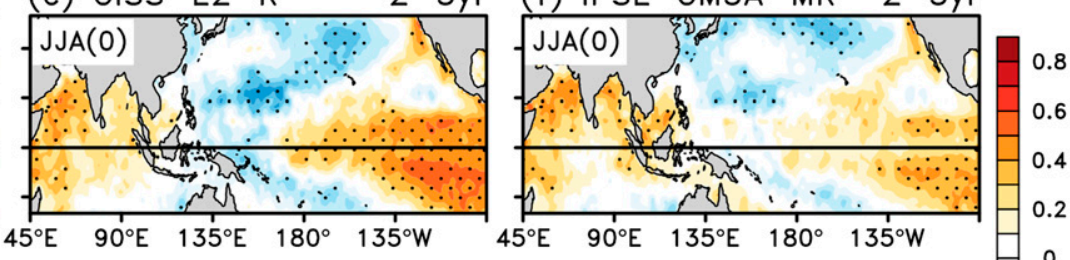

(h) GISS-E2-R 3-5yr
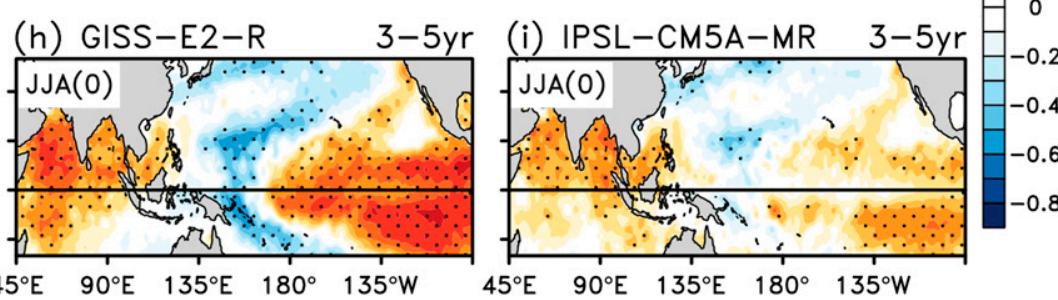

FIG. 10. (a)-(c) As in Fig. 2a, but for the CanAM4, GISS-E2-R, and IPSL-CM5A-MR model simulations, respectively. (d)-(f) As in Fig. 4a, but for the CanAM4, GISS-E2-R, and IPSL-CM5A-MR models, respectively. (g)-(i) As in (d)-(f), respectively, but for the 3-5-yr filtered JJA WPSH indices.

JJA-mean values of these two indices between the observations and the CWB AGCM simulation. The mean HC strength (Fig. 9a) in the simulation $\left(-2.0 \mathrm{~m} \mathrm{~s}^{-1}\right)$ is stronger than that in the observations $\left(-1.7 \mathrm{~m} \mathrm{~s}^{-1}\right)$. The difference between the observations and simulation passes the $95 \%$ confidence level using a two-tailed Student's $t$ test. The mean WC strength (Fig. 9b) in the simulation $\left(1.7 \times 10^{-2} \mathrm{~Pa} \mathrm{~s}^{-1}\right)$ is weaker than that in the observations $\left(1.9 \times 10^{-2} \mathrm{~Pa} \mathrm{~s}^{-1}\right)$, although the difference does not pass the significance test. Therefore, it is reasonable to suggest that an overly strong mean Hadley circulation makes the CWB AGCM unrealistically sensitive to the SST forcing in the central Pacific, leading to an overestimation of the WPSH variability in the 2-3-yr band. Also, an overly weak mean Walker circulation makes the model less sensitive to the SST forcing in the eastern Pacific, which leads to an underestimation of the WPSH variability in the 3-5-yr band.

\section{Verifying the CWB AGCM findings with other AGCMs}

Here we verify our findings from the CWB AGCM by analyzing AMIP simulations from three other AGCMs: the CanAM4, GISS-E2-R, and IPSL-CM5A-MR models. Figures $10 \mathrm{a}-\mathrm{c}$ display the interannual WPSH variability (contours) produced by these models. All the models reasonably produce maximum SLP variability centers over the northeastern Pacific and the WPSH region (see Fig. 2a). We also show in Figs. 10a-c the SLP anomalies (shading) correlated with the WPSH index for all three AGCMs. For the CanAM4 model, positive SLP anomalies (Fig. 10a) in the WPSH region are accompanied by negative SLP anomalies over the Maritime Continent. This SLP correlation is similar to that found in the CWB AGCM (see Fig. 2b). Therefore, we expect the WPSH variability in the CanAM4 model to be dominated by the WPSH response to the CP ENSO. To examine this possibility, we correlate SST anomalies with the 2-3-and the 3-5-yr bands of the WPSH index in this model (Figs. 10d and $10 \mathrm{~g}$ ). The WPSH variability in both bands is indeed associated with negative SST anomalies over the central Pacific and positive SST anomalies over the Maritime Continent, similar to those found in the CWB model (see Figs. $4 b$ and 5b). For the other two AGCMs (the GISSE2-R and IPSL-CM5A-MR), the SLP anomalies correlated with their WPSH indices (Figs. 10b and 10c) do not show an out-of-phase SLP variation between the WPSH region and the Maritime Continent. Instead, an out-ofphase SLP variation is found between the WPSH region and the eastern Pacific. The SST anomalies correlated with their WPSH indices are found to be dominated by 
positive SST anomalies over the eastern Pacific and the Indian Ocean for both the 2-3-yr band (Figs. 10e and 10f) and the 3-5-yr band (Figs. 10h and 10i). Therefore, the WPSH variability in these two particular AGCMs is mostly forced by the EP ENSO forcing. Our analyses indicate that AGCMs can be separated into two groups: one group whose WPSH variability is more sensitive to the forcing from the CP ENSO and the other group whose WPSH variability is more sensitive to the forcing from the EP ENSO. Both the CWB AGCM and the CanAM4 model are in the CP-sensitive group, whereas the GISS-E2-R model and the IPSL-CM5A-MR model are in the EP-sensitive group.

The validity of this grouping can be examined by further calculating the magnitudes of WPSH variability in these models composited for the CP and EP ENSO events. The composite analysis is again performed based on the 12 CP El Niño and 7 EP El Niño events identified in section 4. In the observations, the composite SLP anomalies averaged in the WPSH box are $2.6 \mathrm{hPa}$ for the CP El Niño and $5.0 \mathrm{hPa}$ for the EP El Niño. In the CanAM4 model, we found the composite SLP anomalies averaged in the WPSH box are $3.1 \mathrm{hPa}$ for the CP El Niño and $3.3 \mathrm{hPa}$ for the EP El Niño. Apparently, the WPSH variability forced by the EP SST forcing is underestimated in this model, which is similar to the CWB model. In contrast, the GISS-E2-R and IPSL-CM5AMR models produce much stronger SLP anomalies in the WPSH box for the EP El Niño ( 4.1 and $2.3 \mathrm{hPa}$, respectively) than for the CP El Niño (0.2 and $1.3 \mathrm{hPa}$, respectively). The WPSH variability in these two models is more sensitive to the SST forcing from the eastern Pacific than the forcing from the central Pacific. We also calculated the correlation coefficients between the observed and simulated WPSH indices for the three models. Similar to the CWB AGCM, a larger coefficient for the CanAM4 model is found after the early 1990s (0.75) than before the early 1990s (0.36). In contrast, larger coefficients are found for the GISS-E2-R and IPSL-CM5A-MR models before the early 1990s (0.75 and 0.87 , respectively) than after the early 1990 s $(0.30$ and 0.61 , respectively). These analyses confirm that the models' bias in simulating the WPSH variability is related to their sensitivities to the forcing from the different locations of the tropical Pacific.

We next verify our argument that the model bias is linked to the strengths of the mean Hadley and Walker circulations. As shown in Fig. 11a, the strength of the mean HC in the CanAM4 model $\left(-1.9 \mathrm{~m} \mathrm{~s}^{-1}\right)$ is significantly stronger than that in the observations $\left(-1.7 \mathrm{~m} \mathrm{~s}^{-1}\right)$ at the $95 \%$ confidence level. The strength of the mean WC (Fig. 11b) in the model $\left(2.0 \times 10^{-2} \mathrm{~Pa} \mathrm{~s}^{-1}\right)$ is similar to the observed $\left(1.9 \times 10^{-2} \mathrm{~Pa} \mathrm{~s}^{-1}\right)$. The HC-to-WC
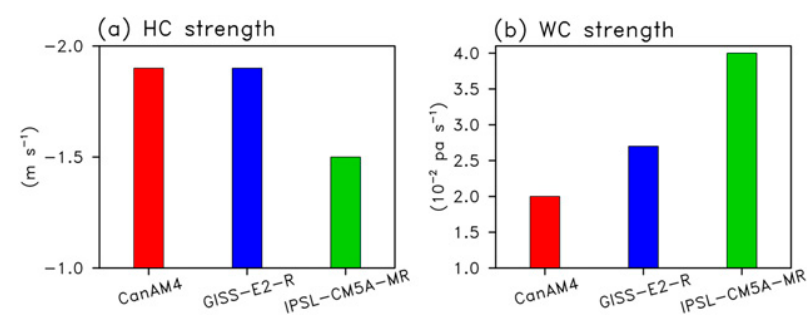

FIG. 11. As in Fig. 9, but for the CanAM4 (red bar), GISS-E2-R (blue bar), and IPSL-CM5A-MR (green bar) models.

ratio normalized by the observed ratio is 1.1 , indicating that the CanAM4 model produces a stronger mean HC. This overly strong HC feature is similar to the CWB AGCM, both of which are in the CP-sensitive model group. In contrast, the GISS-E2-R model produces a normalized HC-to-WC ratio of 0.8. The IPSL-CM5A-MR model produces a normalized ratio of 0.4 . Both of these EP-sensitive models produce a too-strong mean WC. These analyses support our suggestion that the model sensitivity in the WPSH response to the different locations of SST forcing (i.e., central Pacific or eastern Pacific) is influenced by the relative strengths of the mean Hadley and Walker circulations. The models in the CPsensitive group have a strong mean Hadley circulation while the models in the EP-sensitive group have a strong mean Walker circulation.

\section{Summary}

In this study, we have examined the summer WPSH variability in an AMIP-type simulation produced by the CWB AGCM, with a particular focus on its linkages with the two types of ENSO. We find that the CWB AGCM realistically simulates the summer WPSH variability in the 2-3-yr frequency band, which is related to the atmospheric response to the forcing associated with the CP ENSO. In contrast, the model underestimates the $3-5$-yr band of WPSH variability that is related to the atmospheric response to the EP ENSO. This model bias is further confirmed by the results from two sensitivity experiments in which the SST forcing is prescribed over either the CP or EP regions. The model bias is further related to the simulation of the relative strengths of the mean Walker and Hadley circulations. An overly strong mean Hadley circulation may inhibit the model from fully responding to the EP ENSO forcing, whereas an overly strong mean Walker circulation may hinder the model from responding to the CP ENSO forcing. The findings obtained from the CWB AGCM simulation are supported by the results obtained from three other AGCMs (the CanAM4, GISS-E2-R, and IPSL-CM5AMR models). This study concludes that the relative 
strengths of the mean Walker and Hadley circulations are crucial in determining the characteristics of the summer WPSH variability. Our results also imply that model deficiencies in the mean circulation strengths, which are likely related to how deep convection is treated, may affect the ability of AGCMs in simulating and predicting the impacts of the two types of ENSO on Asian-Pacific climate. Alleviation of these model deficiencies are needed for the further improvement of AGCMs.

It should be pointed out that there exists an "El Niño continuum" view (e.g., Giese and Ray 2011), in which EP and CP ENSO events are considered just two extremes of this continuum. Individual ENSO events may actually evolve between these two types during their life cycles. For example, the 1997/98 El Niño event is an EP type of ENSO, but this event began with some positive SST anomalies in the central Pacific [see Fig. 1d in Yu and Paek (2015)] and evolved into a CP La Niña after its decaying phase. Therefore, this EP ENSO event may also contribute to the SST variability in the CP region. The possibility that the SST variability in the central Pacific can also develop in association with EP El Niño events is not considered in this study and deserves further investigation.

Acknowledgments. We thank two anonymous reviewers and Paul Roundy for their valuable comments. We also thank Dr. Ching-Teng Lee for helping the integrations of the sensitivity experiments. This research was supported by a project funded by the Central Weather Bureau of Taiwan and by NSF Grant AGS1233542 of the United States.

\section{REFERENCES}

Ashok, K., S. K. Behera, S. A. Rao, H. Weng, and T. Yamagata, 2007: El Niño Modoki and its teleconnection. J. Geophys. Res., 112, C11007, doi:10.1029/2006JC003798.

Chang, C. P., Y. Zhang, and T. Li, 2000: Interannual and interdecadal variations of the East Asian summer monsoon and tropical Pacific SSTs. Part I: Roles of the subtropical ridge. J. Climate, 13, 4310-4325, doi:10.1175/1520-0442(2000)013<4310: IAIVOT $>2.0 . \mathrm{CO} ; 2$.

Chung, P. H., C. H. Sui, and T. Li, 2011: Interannual relationships between the tropical sea surface temperature and summertime subtropical anticyclone over the western North Pacific. J. Geophys. Res., 116, D13111, doi:10.1029/2010JD015554.

Ek, M. B., K. E. Mitchell, Y. Lin, E. Rogers, P. Grunmann, V. Koren, G. Gayno, and J. D. Tarpley, 2003: Implementation of the upgraded Noah land-surface model in the NCEP operational mesoscale Eta model. J. Geophys. Res., 108, 8851, doi:10.1029/2002JD003296.

Fu, Q., and K. N. Liou, 1992: On the correlated k-distribution method for radiative transfer in nonhomogeneous atmospheres. J. Atmos. Sci., 49, 2139-2156, doi:10.1175/1520-0469(1992)049<2139: OTCDMF $>2.0 . \mathrm{CO} ; 2$.
— , and 1993: Parameterization of the radiative properties of cirrus clouds. J. Atmos. Sci., 50, 2008-2025, doi:10.1175/ 1520-0469(1993)050<2008:POTRPO>2.0.CO;2.

,-- M. C. Cribb, T. P. Charlock, and A. Grossman, 1997: Multiple scattering parameterization in thermal infrared radiative transfer. J. Atmos. Sci., 54, 2799-2812, doi:10.1175/ 1520-0469(1997)054<2799:MSPITI>2.0.CO;2.

Gates, W. L., and Coauthors, 1999: An overview of the results of the Atmospheric Model Intercomparison Project (AMIP I). Bull. Amer. Meteor. Soc., 80, 29-55, doi:10.1175/ 1520-0477(1999)080<0029:AOOTRO >2.0.CO;2.

Giese, B. S., and S. Ray, 2011: El Niño variability in simple ocean data assimilation (SODA), 1871-2008. J. Geophys. Res., 116, C02024, doi:10.1029/2010JC006695.

Gleckler, P., Ed., 2004: The second phase of the Atmospheric Model Intercomparison Project (AMIP2): Toward innovative model diagnostics. Météo-France, $253 \mathrm{pp}$.

Ho, C.-H., J.-J. Baik, J.-H. Kim, D. Y. Gong, and C. H. Sui, 2004: Interdecadal changes in summertime typhoon tracks. J. Climate, 17, 1767-1776, doi:10.1175/1520-0442(2004)017<1767: ICISTT $>2.0 . \mathrm{CO} ; 2$.

Hu, Z.-Z., A. Kumar, B. Jha, W. Wang, B. Huang, and B. Huang 2012: An analysis of warm pool and cold tongue El Niños: Airsea coupling processes, global influences, and recent trends. Climate Dyn., 38, 2017-2035, doi:10.1007/s00382-011-1224-9.

Kalnay, E., and Coauthors, 1996: The NCEP/NCAR 40-Year Reanalysis Project. Bull. Amer. Meteor. Soc., 77, 437-471, doi:10.1175/1520-0477(1996)077<0437:TNYRP>2.0.CO;2.

Kao, H. Y., and J.-Y. Yu, 2009: Contrasting eastern-Pacific and central-Pacific types of ENSO. J. Climate, 22, 615-632, doi:10.1175/2008JCLI2309.1.

Klein, S. A., B. J. Soden, and N. C. Lao, 1999: Remote sea surface temperature variations during ENSO: Evidence for a tropical atmospheric bridge. J. Climate, 12, 917-932, doi:10.1175/ 1520-0442(1999)012<0917:RSSTVD>2.0.CO;2.

Kug, J.-S., F.-F. Jin, and S.-I. An, 2009: Two types of El Niño events: Cold tongue El Niño and warm pool El Niño. J. Climate, 22, 1499-1515, doi:10.1175/2008JCLI2624.1.

Kumar, A., and M. P. Hoerling, 2003: The nature and causes for the delayed atmospheric response to El Niño. J. Climate, 16,13911403, doi:10.1175/1520-0442-16.9.1391.

_ B. Jha, and H. Wang, 2014: Attribution of SST variability in global oceans and the role of ENSO. Climate Dyn., 43, 209220, doi:10.1007/s00382-013-1865-y.

Larkin, N. K., and D. E. Harrison, 2005: On the definition of El Niño and associated seasonal average U.S. weather anomalies. Geophys. Res. Lett., 32, L13705, doi:10.1029/2005GL022738.

Lee, E.-J., J.-G. Jhun, and C.-K. Park, 2005: Remote connection of the northeast Asian summer rainfall variation revealed by a newly defined monsoon index. J. Climate, 18, 4381-4393, doi:10.1175/JCLI3545.1.

Lee, T., and M. J. McPhaden, 2010: Increasing intensity of El Niño in the central-equatorial Pacific. Geophys. Res. Lett., 37, L14603, doi:10.1029/2010GL044007.

Li, J.-L., 1994: On shallow cumulus parameterization scheme for large-scale planetary boundary layers. Ph.D. thesis, University of Wisconsin-Madison, 203 pp.

Liou, C.-S., and Coauthors, 1997: The second-generation global forecast system at the Central Weather Bureau in Taiwan. Wea. Forecasting, 12, 653-663, doi:10.1175/ 1520-0434-12.3.653.

Miyakoda, K., and J. Sirutis, 1986: Manual of the E-physics. Princeton University, 97 pp. [Available from Geophysical 
Fluid Dynamics Laboratory, Princeton University, P.O. Box 308, Princeton, NJ 08542.]

Moorthi, S., and M. J. Suarez, 1992: Relaxed Arakawa-Schubert: A parameterization of moist convection for general circulation models. Mon. Wea. Rev., 120, 978-1002, doi:10.1175/ 1520-0493(1992)120<0978:RASAPO>2.0.CO;2.

Oort, A. H., and J. J. Yienger, 1996: Observed interannual variability in the Hadley circulation and its connection to ENSO. J. Climate, 9, 2751-2767, doi:10.1175/1520-0442(1996)009<2751: OIVITH $>2.0 . \mathrm{CO} ; 2$.

Palmer, T. N., G. Shutts, and R. Swinbank, 1986: Alleviation of a systematic westerly bias in general circulation and numerical weather prediction models through an orographic gravity wave drag parameterization. Quart. J. Roy. Meteor. Soc., 112, 1001-1039, doi:10.1002/qj.49711247406.

Park, J.-Y., J.-G. Jhun, S.-Y. Yim, and W.-M. Kim, 2010: Decadal changes in two types of the western North Pacific subtropical high in boreal summer associated with Asian summer monsoon/El Niño-Southern Oscillation connections. J. Geophys. Res., 115, D21129, doi:10.1029/2009JD013642.

Parks, T. W., and C. S. Burrus, 1987: Design of linear-phase finite impulse-response. Digital Filter Design, John Wiley \& Sons, 33-110.

Rayner, N. A., D. E. Parker, E. B. Horton, C. K. Folland, L. V. Alexander, D. P. Rowell, E. C. Kent, and A. Kaplan, 2003: Global analyses of sea surface temperature, sea ice, and night marine air temperature since the late nineteenth century. J. Geophys. Res., 108, 4407, doi:10.1029/ 2002JD002670.

Saha, S., and Coauthors, 2014: The NCEP Climate Forecast System version 2. J. Climate, 27, 2185-2208, doi:10.1175/JCLI-D-12-00823.1.

Sui, C. H., P. H. Chung, and T. Li, 2007: Interannual and interdecadal variability of the summertime western North Pacific subtropical high. Geophys. Res. Lett., 34, L11701, doi:10.1029/ 2006GL029204.

Taylor, K. E., R. J. Stouffer, and G. A. Meehl, 2012: An overview of CMIP5 and the experiment design. Bull. Amer. Meteor. Soc., 93, 485-498, doi:10.1175/BAMS-D-11-00094.1.

Troen, I., and L. Mahrt, 1986: A simple model of the atmospheric boundary layer: Sensivity to surface evaporation. Bound.Layer Meteor., 37, 129-148, doi:10.1007/BF00122760.

Wang, B., R. Wu, and X. Fu, 2000: Pacific-East Asian teleconnection: How does ENSO affect East Asian climate? J. Climate, 13, 1517-1536, doi:10.1175/1520-0442(2000)013<1517: PEATHD $>2.0 . \mathrm{CO} ; 2$.
__ B. Xiang, and J.-Y. Lee, 2013: Subtropical high predictability establishes a promising way for monsoon and tropical storm predictions. Proc. Natl. Acad. Sci. USA, 110, 2718-2722, doi:10.1073/pnas.1214626110.

Wu, L., B. Wang, and S. Geng, 2005: Growing typhoon influence on east Asia. Geophys. Res. Lett., 32, L18703, doi:10.1029/2005GL022937.

Xie, S. P., K. Hu, J. Hafner, H. Tokinaga, Y. Du, G. Huang, and T. Sampe, 2009: Indian Ocean capacitor effect on Indowestern Pacific climate during the summer following El Niño. J. Climate, 22, 730-747, doi:10.1175/2008JCLI2544.1.

Yu, J.-Y., and K. M. Lau, 2005: Contrasting Indian Ocean SST variability with and without ENSO influence: A coupled atmosphere-ocean GCM study. Meteor. Atmos. Phys., 90, 179191, doi:10.1007/s00703-004-0094-7.

_ , and H. Y. Kao, 2007: Decadal changes of ENSO persistence barrier in SST and ocean heat content indices: 1958-2001. J. Geophys. Res., 112, D13106, doi:10.1029/2006JD007715.

_ , and S.-T. Kim, 2010: Identification of Central-Pacific and Eastern-Pacific types of ENSO in CMIP3 models. Geophys. Res. Lett., 37, L15705, doi:10.1029/2010GL044082.

— Pacific. CLIVAR Exchanges, No. 1, International CLIVAR Project Office, Southampton, United Kingdom, 15-20.

- H. Y. Kao, and T. Lee, 2010: Subtropics-related interannual sea surface temperature variability in the central equatorial Pacific. J. Climate, 23, 2869-2884, doi:10.1175/2010JCLI3171.1.

- H.-Y. Kao, T. Lee, and S. T. Kim, 2011: Subsurface ocean temperature indices for central-Pacific and eastern-Pacific types of El Niño and La Niña events. Theor. Appl. Climatol., 103, 337-344, doi:10.1007/s00704-010-0307-6.

_ M.-M. Lu, and S.-T. Kim, 2012a: A change in the relationship between tropical central Pacific SST variability and the extratropical atmosphere around 1990. Environ. Res. Lett., 7, 034025, doi:10.1088/1748-9326/7/3/034025.

— , Y. Zou, S.-T. Kim, and T. Lee, 2012b: The changing impact of El Niño on U.S. winter temperatures. Geophys. Res. Lett., 39, L15702, doi:10.1029/2012GL052483.

— P.-K. Kao, H. Paek, H.-H. Hsu, C.-W. Hung, M.-M. Lu, and S.-I. An, 2015: Linking emergence of the central Pacific El Niño to the Atlantic multidecadal oscillation. J. Climate, 28, 651-662, doi:10.1175/JCLI-D-14-00347.1.

Zhao, Q., and F. H. Carr, 1997: A prognostic cloud scheme for operational NWP models. Mon. Wea. Rev., 125, 1931-1953, doi:10.1175/1520-0493(1997)125<1931:APCSFO>2.0.CO;2. 